\title{
A ATUAÇÃO DE EX-ARENISTAS E EX-EMEDEBISTAS NA ASSEMBLEIA \\ NACIONAL CONSTITUINTE
}

\section{Rafael Machado Madeira}

\section{Introdução}

O presente artigo tem por objetivo analisar o processo de tomada de decisão dos deputados constituintes a partir de seus vínculos com as organizações partidárias extintas em 1979: Arena e MDB. A hipótese a ser testada é a de que o pertencimento à Arena ou ao MDB constitui-se em variável explicativa promissora para predizer o voto dos constituintes em questóes que demandam um posicionamento ideológico mais definido. Toma-se como parâmetro de análise um conjunto específico de votações em que a relação capital/trabalho está claramente em questão (Diap, 1988). Para além da análise dos dados, pretende-se estabelecer um diálogo com a literatura pertinente sobre o tema, sendo o fio condutor a confrontação de hipóteses.

Para tanto, o artigo está dividido em quatro partes. Após a introdução, apresenta-se o contexto do debate acadêmico sobre análise do desempenho partidário na Câmara dos Deputados, principalmente a partir do exame de índices de fidelidade partidária em votações de plenário (tanto no contexto da Constituinte, como ao longo da década de 1990). A terceira parte é central no artigo, visto que, para além da explicação da metodologia empregada, são analisados os dados que permitem mensurar a relação entre o posicionamento dos deputados e seus antigos vínculos partidários. A seguir, a presente hipótese será confrontada com duas hipóteses alternativas (origem socioocupacional e territorial dos deputados) para a compreensão do comportamento dos constituintes. Por fim, serão realizadas as considerações finais. 


\section{Partidos, votaçóes em plenário e a Constituinte}

Ao analisar a influência dos ex-arenistas nos anos de 1980 e 1990, Power (2000) identifica e analisa três momentos em que este grupo teria atuado de forma homogênea: na própria Assembleia Nacional Constituinte (ANC) via "Centrão" em 1987-1988, atuando na base de sustentação do presidente Fernando Collor de Melo (sobretudo em 1992) e, por fim, como membro da coalizão que em 1994 elegeu Fernando Henrique Cardoso à presidência da República. Com relação ao primeiro período, o autor afirma que:

Os ex-arenistas, é claro, não formam um partido no seu sentido litreral, mas desde 1985 este grupo atua em conjunto, informalmente e de forma contínua, a partir de dois modos principais. Primeiro, o grupo atuou como um movimento ideológico e tático na Assembléia $\mathrm{Na}$ cional Constituinte (ANC) de 1987-88 para se contrapor ao que eles percebiam como um viés de extrema esquerda na Assembléia. Este movimento ideológico, o Centrão, foi em grande parte reativo. Quase tão rapidamente como foi formalmente constituído, este grupo desintegra-se, revelando obstáculos interessantes para a formação de um único e grande partido político conservador no Brasil (Power, 2000, p. 184, tradução minha).

Este período que compreende as fases de elaboração, negociaçãa e votação da Constituição brasileira representa um dos momentos mais ricos e menos analisados da história política brasileira recente. $\mathrm{O}$ objetivo deste artigo é utilizar a Assembleia $\mathrm{Na}$ cional Constituinte como parâmetro para examinar o comportamento de ex-arenistas e ex-emedebistas nas votações em plenário. A escolha deste período justifica-se principalmente por dois motivos, o primeiro substantivo e o segundo operacional.

Análises da disciplina partidária nas votações em plenário como as realizadas por Figueiredo e Limongi (1999) e por Leoni (2002) na década de 1990 apresentam um panorama geral consistente apontando para o controle que as lideranças partidárias e o Executivo possuem sobre as diferentes bancadas. Tal análise é, contudo, passível de críticas. Em um estudo abrangente, o número relativamente pequeno de votações polêmicas e/ou que envolvam discussão programática mais consistente encontra-se diluído em um universo de votaçôes não polêmicas e/ou sem importância do ponto de vista ideológico ou programático. Esforços foram feitos no sentido de resolver esta questão a partir da análise somente das votações em que se identifica uma divisão mínima do plenário. Contudo, o fato de o plenário se dividir em determinada votação não garante que esta envolva um posicionamento ideológico, pois, para além da ideologia, outros aspectos podem se constituir na causa da divisão (relação governo versus oposiçãa, questôes federativas etc.). Destarte, na análise da disciplina partidária no Brasil o primeiro passo foi dado: a constatação de que no agregado os partidos políticos brasileiros são significativamente mais disciplinados do que se imaginava anteriormente. Um segundo teste deve ser, contudo, realizado tendo-se como parâmetro um conjunto mais restrito de votaçōes, no qual questôes programáticas estejam em jogo.

$\mathrm{O}$ aspecto operacional refere-se ao fato de a obra intitulada Quem foi quem na Constituinte (Diap, 1988) apontar de forma sistemática o resultado individual de dez das mais relevantes e controversas votaçôes da ANC. Isto é, do conjunto foram escolhidas em cada turno dez votações das que mais impactavam os interesses da "classe trabalhadora". Para este conjunto específico, o Diap aponta com precisão o processo de tomada de decisão de cada constituinte, atribuindo a cada um uma nota final que ilustra o grau de comprometimento com os problemas e os interesses dos trabalhadores.

Este material é uma excelente fonte de dados e um bom critério para identificar os grupos mais conservadores e os mais progressistas. De um lado, permite distinguir os deputados federais dos senadores (o que é crucial para a presente análise); de outro, examina dez votaçôes em cada turno, que, por se tratar de alguns dos temas mais polêmicos da Constituinte, têm grande relevância política e programática.

Quando se analisam votações em plenário, uma das primeiras hipóteses a ser testada é a filiação partidária dos deputados. Como vimos, as análises de Figueiredo e Limongi (1998) e Leoni (2002) 
atestam para a relevância desta variável. Se esses estudos se preocupam em mapear o comportamento de deputados e partidos de uma forma abrangente, outros autores se esforçam por testar a capacidade dos partidos para condicionar o voto de suas bancadas em contextos específicos em que esta capacidade é colocada em xeque. O estudo de Mainwaring e Liñan (1998) é um bom exemplo desse tipo de iniciativa. Os autores examinam o grau de disciplina dos partidos políticos brasileiros justamente na ANC, centrando o foco de análise apenas nas votações definidas como polêmicas:

Disciplina ou unidade partidária significa aqui a proporção com que os membros de um partido votam do mesmo modo em votaçōes nominais polêmicas. (Definimos votações polêmicas como aquelas em que um mínimo de $25 \%$ dos parlamentares vota contra a proposta vencedora.) Um partido disciplinado é aquele em que seus membros votam de forma unida nas votações nominais polêmicas. Mesmo com partidos indisciplinados, os parlamentares do mesmo partido normalmente votam de forma coesa, mas isso se dá porque muitas questōes legislativas são consensuais, tanto internamente a cada grupo como no plenário em geral. No caso das questões que racham o parlamento, os partidos indisciplinados estão frequentemente divididos (Idem, p. 108)

Os autores identificaram níveis de disciplina partidária mais baixos do que os encontrados na década de 1990. Cabe ressaltar que a comparação entre estas análises não pode ser feita de forma direta, uma vez que se tratava de períodos diferentes, nos quais as regras institucionais de funcionamento do Legislativo eram distintas, e também pelo fato de Mainwaring e Liñan agruparem em sua análise o Congresso como um todo, vale dizer, deputados federais e senadores, enquanto Figueiredo e Limongi (1998) e Leoni (2002) analisam apenas os deputados federais.

A partir do estudo de Mainwaring e Liñan identifica-se que as situações de divisão em plenário tendem a repercutir muito mais no interior de cada partido (dividindo suas respectivas bancadas) do que entre os partidos (isto é, onde a divisão se daria entre partidos discordantes, mas coesos internamente). Em suma, a análise do padrão de votação apenas dos deputados federais constituintes é em um bom parâmetro para se identificar até que ponto a filiação a seus respectivos partidos, ou os vínculos com as duas antigas agremiaçōes, explica o comportamento dos deputados em um dos períodos mais relevantes da fase de transição e consolidação da democracia brasileira.

Para além dos estudos já citados, ao examinar este mesmo período Souza (2001) afirma que um exame realizado somente a partir da filiação partidária dos deputados seria incapaz de dar conta da análise da Assembleia Constituinte brasileira. De acordo com a autora:

A ANC foi marcada por confrontos em algumas matérias, coalizões na maioria dos casos e por adiamentos quando o consenso não podia ser alcançado. Coalizões eram feitas e refeitas constantemente. Praticamente, para cada questão específica, um bloco extrapartidário era constituído, o qual logo se desfazia (Idem, p. 520)

É consenso na literatura especializada que, ao menos durante a $\mathrm{ANC}$, os partidos não se constituíram em variáveis relevantes na definição do voto de suas respectivas bancadas. Em vez dos partidos, as coalizões seriam formadas caso a caso com base no tipo de questão em jogo a cada votação. Em tal cenário, vários seriam os critérios a partir dos quais o conjunto dos deputados federais poderia se agrupar: estados menos desenvolvidos versus estados mais desenvolvidos, capital versus trabalho, coalizão governista versus oposição, estatizantes versus liberais e defensores do status quo versus reformadores (presidencialistas versus parlamentaristas, por exemplo). Isto é, na ausência dos partidos políticos, seria praticamente inviável a escolha de um critério que pudesse dar conta a priori da análise do processo de tomada de decisão dos deputados federais brasileiros.

\section{Metodologia e análise dos dados}

O objetivo aqui é testar um novo critério de análise capaz de identificar tendências gerais (pa- 
drões de votação) que deem conta da explicação deste processo de tomada de decisão dos constituintes. Esse critério toma como base o pertencimento dos deputados federais constituintes aos partidos Arena e MDB.

Se a análise da disciplina partidária indica que os partidos políticos não dão conta de explicar o processo de tomada de decisão dos constituintes (Power, 2000; Mainwaring e Liñan, 1998; Souza 2001), o presente estudo buscará identificar se o vínculo aos dois antigos partidos constitui-se em critério mais promissor para explicar este fenômeno. Como esses partidos foram extintos, não tem sentido falar em disciplina partidária. Assim, se a hipótese aqui for comprovada, identificar-se-á a existência de um grau significativo de coesão, e não de disciplina, ${ }^{1}$ entre os remanescentes de Arena e MDB. Para se entender como o trabalho do Diap foi realizado é importante salientar que:

Escolheu-se as dez matérias mais importantes [referentes aos direitos sociais dos trabalhadores] de cada turno de votações e se fixou um peso para cada uma delas, variando de zero a um ponto e meio para cada. $\mathrm{O}$ constituinte que compareceu e votou "sim" ganha pontos, o que se absteve, estava ausente ou votou "não" deixa de ganhar menção.

Assim, se o constituinte não faltou às provas (votações), terá três opções: deixa a prova em branco (abstenção), acerta a prova (vota "sim") ou faz a prova errada (vota "não). Se não fizer a prova: tira zero, é óbvio. Se fizer a prova errada, tira zero. Se deixar a prova em branco tira zero também e se fizer a prova correta, ganha pontos (Diap, 1988, p. 29).

Este critério (em que tanto o voto negativo como a abstenção ou a ausência não marcam pontos) para o estabelecimento do ranking dos deputados faz sentido, pois para a aprovação de uma emenda ao texto constitucional era necessária a maioria absoluta dos votos e não a maioria relativa (maioria do quorum de cada votação). Destarte, o efeito prático de uma abstenção ou ausência era o mesmo de um voto negativo à emenda em questão. $\mathrm{O}$ exame do com- portamento dos deputados em cada votação permite identificar que a estratégia de se ausentar do plenário ou de se abster para não sofrer o desgaste de votar abertamente contra os trabalhadores foi frequentemente utilizada, principalmente por ex-arenistas.

As votações que servem como parâmetro para a formação do ranking no primeiro turno são as seguintes: estabilidade, 40 horas, turno de seis horas, salário mínimo, prescrição, ${ }^{2}$ férias, piso salarial, direito de greve, aviso prévio mínimo de 30 dias e comissão de fábrica. ${ }^{3}$ No segundo turno, foram escolhidas: estabilidade, 40 horas, turno de seis horas, direito de greve, aviso prévio proporcional, estabilidade do dirigente sindical, sindicato como substituto processual, participação em órgãos de seu interes$\mathrm{se}^{4}$ e a autoaplicabilidade dos direitos sociais. ${ }^{5}$

O fato de a fundação do PSDB ter ocorrido exatamente entre o primeiro e o segundo turnos de votações faz com que, em primeiro lugar, não seja possível examinar no recém-formado partido o ranking de seus deputados. Em segundo, os índices gerais do PMDB provavelmente estão situados um pouco mais à direita do que foi aqui encontrado, visto que a saída de um grupo majoritariamente formado por ex-emedebistas deve ter como consequência o deslocamento da média geral do partido no segundo turno. Devido à indissociação entre tucanos e peemedebistas não será possível mensurar se há uma correspondência entre a maioria ex-emedebista e uma tendência ao posicionamento mais elevado no ranking do Diap, o que iria ao encontro do argumento principal deste artigo. Tal problema, contudo, não prejudica o principal objetivo da análise, uma vez que a migração partidária após o fim do bipartidarismo não afeta a filiação partidária anterior, ou seja, um ex-arenista será sempre um ex-arenista, seja no PDS, no PMDB ou no PSDB.

O procedimento para a análise dos dados foi realizado principalmente em duas etapas. Em primeiro lugar, construiu-se um banco de dados (SPSS) a respeito de cada constituinte, sua filiação partidária na Constituinte, filiações anteriores (participação ou não no bipartidarismo) e demais dados referentes à carreira política (cargos ocupados, profissão etc.). Neste banco, cada votação analisada pelo Diap passa a ser uma variável. Dessa forma, tem-se acesso ao 
posicionamento dos constituintes para cada votação específica. Ao examinar o comportamento geral de cada um, o Diap criou uma nova variável ("média final") que corresponde ao grau de comprometimento dos deputados aos interesses dos trabalhadores. Esse grau é representado por uma escala que varia de zero (deputado contrário aos interesses dos trabalhadores) a dez (deputado defensor dos interesses dos trabalhadores) e é o resultado da média das "notas" obtidas por cada deputado no primeiro e no segundo turnos. Como esta escala é fruto do comportamento dos deputados em todas as votações analisadas nos dois turnos, toma-se esta variável como parâmetro da média do posicionamento dos constituintes.

Em segundo lugar, definiu-se um critério para a análise dos dados coletados. Em um primeiro momento, optou-se por um critério simples de agrupamento dos dados: dividir a média final em apenas dois grupos (de zero a 5 e de 5,1 a 10). No entanto, logo se identificou que tal procedimento criaria um contexto de polarização artificial entre os dois grupos. Isto é, mesmo os deputados que não possuíssem posiçōes político-ideológicas claras e que votassem ora a favor ora contra os interesses dos trabalhadores seriam equivocadamente tratados como deputados com posições claramente definidas. Uma vez de posse dos dados e para distinguir os deputados mais sensíveis dos menos sensíveis à pressão dos trabalhadores (levando-se em consideração também a existência desse grupo intermediário), a média final dos deputados foi organizada em três grupos: de zero a 3,9 (deputados que votaram sistematicamente contra os interesses dos trabalhadores), de 4 a 6 (deputados que não podem ser definidos nem como apoiadores, nem como oposi- tores sistemáticos dos interesses dos trabalhadores) e acima de 6 (deputados que votaram sistematicamente a favor dos interesses dos trabalhadores).

A análise do comportamento geral dos deputados federais na ANC agrupados por filiação partidária representa uma primeira aproximação na identificação de seu padrão de votação. Entre as bancadas analisadas, o PT é bancada mais disciplinada. Não é novidade tampouco a identificação do PMDB e do PTB como as bancadas mais indisciplinadas (Mainwaring e Liñan, 1998; Figueiredo e Limongi, 1998).

Embora com níveis variados de homogeneidade e apesar de todos os partidos, com exceção do $\mathrm{PT}$, indicarem a existência de divisões internas às bancadas, cabe fazer menção à existência de uma coerência entre posição majoritária no interior de cada bancada e posição tradicionalmente atribuída a cada partido com relação aos direitos e às prerrogativas dos trabalhadores. Ao se estabelecer um contínuo entre os partidos que mais se opuseram e os que mais apoiaram as reivindicações dos trabalhadores, identifica-se que PDS com $82 \%$ e PFL com $78 \%$ são oponentes sistemáticos, $\mathrm{PTB}$ e $\mathrm{PMDB}$, nesta ordem, ocupam uma posição intermediária e que PDT com $92 \%$ e PT com $100 \%$ são os apoiadores sistemáticos dos direitos dos trabalhadores.

É digno de nota também o fato de este estudo ter chegado ao mesmo resultado encontrado por Mainwaring e Liñan (1998) no que tange ao ranking dos partidos pelo grau de homogeneidade de suas respectivas bancadas. Em ambos, a ordem é a seguinte: PT, PDT, PDS, PFL, PTB e PMDB. Esses dados vão também ao encontro dos achados de Figueiredo e Limongi (1998, capítulo 3), que identificam os

Quadro 1

Quem foi Quem na Constituinte: por partido

\begin{tabular}{llllllll}
\hline Partido & PDS & PFL & PMDB & PTB & PDT & PT & Total \\
\hline Nota até 3,9 & $27 / 82 \%$ & $89 / 78 \%$ & $78 / 31 \%$ & $3 / 18 \%$ & $1 / 4 \%$ & - & $203 / 43 \%$ \\
\hline Nota 4 a 5,9 & $3 / 9 \%$ & $11 / 10 \%$ & $45 / 18 \%$ & $5 / 29 \%$ & $1 / 4 \%$ & - & $71 / 15 \%$ \\
\hline Acima de 6 & $3 / 9 \%$ & $14 / 12 \%$ & $127 / 51 \%$ & $9 / 53 \%$ & $22 / 92 \%$ & $16 / 100 \%$ & $202 / 42 \%$ \\
\hline Total & $33 / 100 \%$ & $114 / 100 \%$ & $253 / 100 \%$ & $17 / 100 \%$ & $24 / 100 \%$ & $16 / 100 \%$ & $476 / 100 \%$ \\
\hline
\end{tabular}

Fonte: Diap (1988). 
partidos políticos de esquerda como os mais homogêneos em plenário no início da década de 1990.

Logo depois do PT e do PDT, aparecem justamente os dois partidos, principais herdeiros da Arena, mais à direita, que possuem as bancadas com comportamento mais homogêneo nas votações examinadas. Talvez a principal diferença entre os dados apresentados e os identificados pelos outros autores seja o fato de que PDS e PFL possuem índices bem mais altos de homogeneidade em comparação com a legislatura seguinte. Os dados apresentados a seguir apontam como explicação possível para a diminuição da homogeneidade dessas bancadas na década de 1990 o fato de haver uma forte coesão entre os membros que vieram da Arena, enquanto seus novos quadros - os não remanescentes - não possuem o mesmo grau de coesão.

Os dados presentes no Quadro 1 trazem aspectos que merecem exame mais detido. Como se trata de um conjunto de votaçôes que, embora relevante e polêmico, é muito específico (apenas dez votações em cada turno), não se pode com base nessa amostra pouco representativa refutar a tese $\mathrm{da}$ pouca coesão/disciplina dos partidos políticos brasileiros. Mainwaring e Liñan (1998), por exemplo, trabalham com um conjunto de votaçôes significativamente mais amplo (363 votaçôes entre os dois turnos), o que permite inferir com maior segurança o grau de homogeneidade de cada bancada. Contudo, o objetivo deste artigo não é ir contra o argumento da falta de homogeneidade das bancadas, mas, sim, buscar uma explicação plausível.

Apesar da existência de uma coerência das diferentes bancadas em relação à posição de cada partido no espectro político-ideológico, as bancadas de pelo menos dois dos principais partidos políticos brasileiros possuem graus significativos de divisão interna. $\mathrm{O}$ que se pretende a partir dessa constatação é dar o segundo passo na análise: não basta afirmar que os partidos não atuaram de forma coesa e/ou disciplinada na Constituinte, é preciso tentar identificar o porquê deste comportamento.

Quem são os deputados que, nas bancadas mais divididas, não seguiram suas respectivas maiorias? O Quadro 2 traz informaçôes acerca do grau de coesão não dos partidos aos quais os deputados eram filiados durante a ANC, mas sim dos "anti- gos partidos", isto é, o conjunto dos deputados é agora dividido em três grupos: os ex-arenistas, os ex-emedebistas e os não remanescentes.

Quadro 2

Quem foi Quem na Constituinte: Arena versus MDB

\begin{tabular}{llll}
\hline $\begin{array}{l}\text { Origem } \\
\text { partidária }\end{array}$ & Votação & Frequência & Percentual \\
\hline Ex-arenistas & Nota até 3,9 & 97 & 69 \\
& Nota 4 a 5,9 & 24 & 17 \\
& Acima de 6 & 21 & 14 \\
& Total & 142 & 100 \\
\hline Ex-emedebistas & Nota até 3,9 & 26 & 18 \\
& Nota 4 a 5,9 & 21 & 14 \\
& Acima de 6 & 101 & 68 \\
& Total & 148 & 100 \\
\hline Não & Nota até 3,9 & 73 & 42 \\
remanescentes & Nota 4 a 5,9 & 24 & 14 \\
& Acima de 6 & 78 & 44 \\
& Total & 175 & 100 \\
\hline
\end{tabular}

Fonte: Diap (1988).

De uma forma geral, identifica-se no Quadro 2 uma nítida distinção entre os remanescentes e os não remanescentes, qual seja, tanto ex-arenistas como ex-emedebistas possuem uma tendência claramente definida (de apoio, ou de oposição aos interesses dos trabalhadores). Em ambos os casos, praticamente $70 \%$ de cada bancada se posicionou claramente em um dos polos nas votaçóes examinadas. Além disso, nos dois casos a posição minoritária não alcança sequer $20 \%$ de seus membros. Não apenas a posição de ex-arenistas e ex-emedebistas é nítida para um ou outro polo, como também o percentual dos seus respectivos grupos majoritário e minoritário é praticamente idêntico. Ou seja, o comportamento de ex-arenistas e de ex-emedebistas nas votações examinadas não é apenas diferente, mas simetricamente oposto.

Os não remanescentes, por sua vez, não possuem uma posição claramente definida a favor ou contra os interesses dos trabalhadores. Dos três grupos, este é o único em que se identifica uma clara divisão interna em que ambos os polos possuem praticamente 
o mesmo peso. Observa-se que no agregado, ex-emedebistas e ex-arenistas possuem padrão de votação distinto e claramente definido, algo que não ocorre entre os não remanescentes. Em outras palavras, a filiação à Arena ou ao MDB é forte indicador do comportamento de um deputado nas votações em plenário. $\mathrm{O}$ mesmo não ocorre com os não remanescentes. Pertencer a essa categoria não contribui para a previsibilidade de seu voto. Por fim, no cruzamento dos Quadros 1 e 2, a distribuição de preferência dos não remanescentes é praticamente idêntica à do conjunto dos deputados federais (última coluna do Quadro 1).

Comparando-se esses três grupos com os partidos identificados no primeiro quadro, observa-se que PT, PDT, PDS e PFL possuem bancadas mais homogêneas do que as dos ex-emedebistas e ex-arenistas. Isto é, para a previsão do comportamento dos deputados destas bancadas a variável "filiação partidária" é mais promissora do que a variável "remanescente/não remanescente". ${ }^{6}$ Em um primeiro momento parece que para 187 deputados não faria fazia muito sentido identificar se eles foram filiados à Arena ou ao MDB. No entanto, para os 270 filiados ao PMDB e ao PTB a variável "remanescente/não remanescente" é relevante, pois a probabilidade de um deputado do PMDB votar contra os interesses dos trabalhadores é de quase um terço, enquanto para um ex-emedebista cai para apenas $18 \%$. Logo, para a maioria dos deputados constituintes, o fato de ter sido filiado à Arena ou ao MDB constitui-se em variável relevante.

$\mathrm{Na}$ realidade, a relevância dessa variável não se restringe aos deputados filiados ao PMDB e ao PTB; ela pode ser utilizada também para explicar o comportamento desviante de alguns deputados quando comparado à média de seus companheiros de legenda. Tal procedimento será realizado com base no cruzamento entre a filiação dos deputados constituintes a seus respectivos partidos e a categoria a que pertencem: ex-arenistas, ex-emedebistas ou não remanescentes.

\section{Quadro 3}

\section{Quem foi Quem na Constituinte: Filiação Atual versus Filiaçáo Antiga}

\begin{tabular}{lllll}
\hline Partido & Média Final & Ex-arenistas & Ex-emedebistas & Não remanescentes \\
\hline PDS & De 0 a 3,9 & $20 / 87 \%$ & - & $6 / 67 \%$ \\
& De 4 a 5,9 & $2 / 9 \%$ & - & $1 / 11 \%$ \\
& 6 ou mais & $1 / 4 \%$ & - & $2 / 22 \%$ \\
& Total & $23 / 100 \%$ & - & $9 / 100 \%$ \\
\hline PFL & De 0 a 3,9 & $54 / 79 \%$ & $3 / 100 \%$ & $29 / 73 \%$ \\
& De 4 a 5,9 & $6 / 9 \%$ & - & $5 / 12 \%$ \\
& 6 ou mais & $8 / 12 \%$ & - & $6 / 15 \%$ \\
& Total & $68 / 100 \%$ & $3 / 100 \%$ & $40 / 100 \%$ \\
\hline PMDB & De 0 a 3,9 & $19 / 46 \%$ & $23 / 18 \%$ & $33 / 40 \%$ \\
& De 4 a 5,9 & $14 / 34 \%$ & $20 / 16 \%$ & $13 / 16 \%$ \\
& 6 ou mais & $8 / 20 \%$ & $82 / 66 \%$ & $37 / 44 \%$ \\
& Total & $41 / 100 \%$ & $125 / 100 \%$ & $83 / 100 \%$ \\
\hline PTB & De 0 a 3,9 & $1 / 25 \%$ & - & $2 / 29 \%$ \\
& De 4 a 5,9 & $1 / 25 \%$ & $1 / 20 \%$ & $3 / 42 \%$ \\
& 6 ou mais & $2 / 50 \%$ & $4 / 80 \%$ & $2 / 29 \%$ \\
& Total & $4 / 100 \%$ & $5 / 100 \%$ & - \\
\hline PDT & De 0 a 3,9 & $1 / 33 \%$ & - & $1 / 100 \%$ \\
& De 4 a 5,9 & - & - & $10 / 91 \%$ \\
& 6 ou mais & $2 / 67 \%$ & $9 / 100 \%$ & $11 / 100 \%$ \\
\hline Potal & $3 / 100 \%$ & $9 / 100 \%$ & - \\
& De 0 a 3,9 & - & - & - \\
& De 4 a 5,9 & - & - & $14 / 100 \%$ \\
& 6 ou mais & - & $2 / 100 \%$ & $14 / 100 \%$ \\
\hline
\end{tabular}

Fonte: Diap (1988). 
O Quadro 3 permite identificar, em primeiro lugar, que se o grau de fidelidade partidária do PMDB é baixo, tal fato não se deve ao comportamento dos ex-emedebistas que é quase idêntico ao do conjunto dos remanescentes do $\mathrm{MDB}$. $\mathrm{Ou}$ seja, os ex-emedebistas que formam esta bancada não são os responsáveis por sua divisão interna. Os não remanescentes, por sua vez, são o grupo mais heterogêneo, e, ainda, o que mais contribui para a divisão da bancada peemedebista. Como o peso dos ex-emedebistas é significativamente maior do que o dos demais grupos, sua posição majoritária define, logicamente, a posição majoritária da bancada.

Se a maioria dos não remanescentes não segue a tendência majoritária, a divisão da bancada se expressa claramente no comportamento dos peemedebistas oriundos da Arena - 80\% deste grupo votou contra os interesses dos trabalhadores. Embora dividido internamente, o grupo dos ex-arenistas filiados ao PMDB mantém coerência em relação à sua filiação anterior, visto que apenas 8 de um total de 41 situam-se claramente contra a posição majoritária entre os ex-arenistas. A diminuição do grau de homogeneidade dos ex-arenistas do PMDB em relação aos ex-arenistas que permaneceram no PDS ou no PFL é digna de nota, mas não o suficiente para descaracterizar o posicionamento majoritário dos ex-arenistas de nutrir pouca simpatia pelos interesses dos trabalhadores.

Pode-se identificar aqui a confluência de dois processos que ajudam a compreender melhor o impacto de ex-arenistas e ex-emedebistas ao longo do período de fundação do novo multipartidarismo. De um lado, o estudo de carreiras permitiu observar a coerência que os remanescentes de ambos os partidos mantêm com suas antigas legendas mensurada pela consistência ideológica de suas posições. De outro, se os ex-emedebistas encontram-se circunscritos aos partidos à esquerda do $\mathrm{PMDB}$, o mesmo não se verifica em relação aos ex-arenistas, que se encontram representados em todos os principais partidos políticos analisados (à exceção do PT). Isso sugere a hipótese de que a dispersão arenista foi um elemento desestruturador importante do atual multipartidarismo, principalmente em sua fase inicial (Madeira, 2006).

$\mathrm{Na}$ medida em que os ex-arenistas mantinham um comportamento que mais se assemelhava ao seu antigo partido do que à posição majoritária nos seus partidos de então, isto é, na medida em que embora distribuídos em vários partidos, os ex-arenistas mantêm-se coesos ideologicamente, constata-se que a "diáspora arenista" acentuou a dificuldade destes partidos em cristalizar identidades próprias.

No caso do PTB, esta mudança de comportamento torna-se mais evidente quando $50 \%$ dos ex-arenistas filiados a este partido caracterizam-se por possuir médias acima de oito. Se entre os ex-arenistas identifica-se um comportamento distinto do esperado, o mesmo não ocorre entre os ex-emedebistas filiados ao PTB, que apresentam um comportamento homogêneo e com altas médias finais. No entanto, por ser muito baixo o número de ex-arenistas e de ex-emedebistas filiados ao PTB esta análise perde capacidade explicativa.

Também não é representativo o número de ex-arenistas filiados ao PDT. Contudo, vale a pena chamar a atenção para alguns aspectos nesse sentido. Em primeiro lugar, identificou-se que apesar de terem sido classificados como sensíveis aos interesses dos trabalhadores, as médias finais dos dois ex-arenistas filiados no PDT foram 6,2 e 6,5. Ambos estão próximos da fronteira entre os apoiadores e os deputados sem uma clara definição no que tange ao apoio ou à oposição aos interesses dos trabalhadores. Ao comparar os índices de disciplina das diferentes bancadas entre o primeiro e o segundo turno das votações, Mainwaring e Liñan mostram uma significativa estabilidade dos índices. $\mathrm{O}$ único caso de mudança expressiva ocorre justamente no PDT:

Causado pela defecção de três conservadores que baixavam os níveis do partido no primeiro período. [...] O PDT tinha três representantes conservadores que costumavam votar contra a maioria do partido. Os três transferiram-se para partidos conservadores antes do final da ANC, dois deles juntaram-se ao PFL e um ao PTB (Mainwaring e Liñan, 1998, p. 119).

Em outras palavras, após terem sido eleitos por um partido de esquerda, esses três deputados acabaram por deixar a legenda que os elegeu antes do final da legislatura. Quanto aos ex-emedebistas, 
filiados tanto no PDT como no PT, há um comportamento homogêneo.

Por fim, os ex-arenistas possuem um comportamento significativamente coeso tanto no PFL como no PDS, o que corrobora o argumento de que ter sido filiado à Arena ou ao MDB constitui-se em um critério consistente de definição de um padrão de comportamento, ao menos em relação às questões envolvendo a relação capital versus trabalho tratadas na ANC. Os ex-emedebistas filiados a estes partidos não seguiram a tendência que a sua antiga filiação presumiria. Deve-se salientar que assim como no PDT e no PTB, o número de ex-emedebistas aqui (apenas 3 no PFL) é extremamente reduzido e, consequentemente, não representativo.

$\mathrm{Se}$ os ex-emedebistas do PMDB apresentam um comportamento quase idêntico ao dos ex-emedebistas como um todo, os ex-arenistas filiados ao PDS e ao PFL caracterizam-se por um comportamento ainda mais homogêneo ao identificado no conjunto dos ex-arenistas. Além desse aspecto, e ao contrário do PMDB e do PTB, tal unidade é reforçada pelo comportamento homogêneo também dos não remanescentes desses partidos, embora em menor escala. Por fim, analisando-se as três maiores bancadas, que contêm trezentos deputados, conclui-se que a grande maioria dos ex-arenistas e dos ex-emedebistas comportou-se como o esperado.

A análise das votações demonstra que embora exista variação de um partido para outro, é possível identificar a existência de um padrão claro de comportamento, seja entre ex-arenistas, seja entre ex-emedebistas. Tal aspecto ajuda a explicar, inclusive, o fato de o PMDB ser a legenda mais afetada pela falta de homogeneidade de sua bancada. A coexistência de ex-arenistas e ex-emedebistas contribui para a diminuição do grau de homogeneidade, uma vez que esses grupos tendem a seguir, nas votaçōes em questão, o padrão de votação de suas antigas legendas. $\mathrm{Na}$ declaração ao Jornal do Brasil do então deputado federal Dasso Coimbra, ex-arenista filiado ao PMDB do Rio de Janeiro pode-se identificar o quanto os antigos vínculos ainda conferiam aos ex-arenistas um "sentido de grupo" nas votações em plenário:

Consultado sobre a origem do Centrão, o deputado Dasso Coimbra (PMDB-RJ), um dos líderes do movimento, disse que ideologicamente falando ele ainda estava na Arena, que era, a seu ver, "claramente um partido de centro". Ele continua: "Este é o momento de reconstrução (reaglutinação) das ideologias. Cada constituinte é soberano na sua vontade, e os partidos já não têm mais qualquer importância [...]. Na elaboração da Constituição, não há partidos. Eles existiram somente durante a fase dos comitês porque os membros das comissões foram nomeados pelos líderes partidários. Agora estamos no plenário, o que permite a reunião de forças comuns. A Arena é um ponto de referência e não há problema nisso (Apud Power, 2000, p. 188, tradução minha).

Durante praticamente dez anos, Arena e MDB não se constituíram e não eram vistos como variáveis relevantes para se entender a dinâmica política e eleitoral brasileira. Aspectos como a artificialidade do bipartidarismo relegavam essas legendas a um segundo plano. Contudo, após este período longo de maturação, identificou-se (Madeira, 2006) que Arena e MDB passam paulatinamente a se constituir em variáveis relevantes não somente nas eleiçōes realizadas na segunda metade da década de 1970, como também após a sua extinção, ao longo da década seguinte, chegando até a ANC. E a sua relevância é atestada na citação anterior, que é uma ilustração clara da dinâmica identificada por Pierson:

Assim, os processos sociais podem ser não somente "lentos"; eles também podem exigir um longo tempo, porque [normalmente] há uma separação significativa entre uma causa e suas consequências. Em ambos os casos, o processo completo pode não ser visível a menos que a análise considere um espaço substancial de tempo (2004, p. 97 , tradução minha).

Até aqui foi possível constatar que tanto ex-emedebistas como ex-arenistas mantêm níveis surpreendentes de homogeneidade. A principal diferença entre os dois grupos é que o estudo de carreiras identificou que enquanto os ex-emedebistas mantêm-se circunscritos em apenas alguns dos principais partidos políticos (basicamente PMDB, 
PSDB, PDT e, em menor medida, PTB), os remanescentes da Arena ampliam muito mais o seu leque, "contaminando" justamente os principais herdeiros do antigo MDB. Para além de explicar o comportamento dos constituintes em plenário, este dado ajuda a explicar o aumento dos custos de transação identificados, no PMDB, desde a década de 1980, e, no PSDB, a partir da década de 1990.

A hipótese aqui examinada passou no primeiro teste: existe um padrão claro de comportamento entre remanescentes de Arena/MDB nas votações examinadas na ANC. No entanto, será que é realmente a filiação partidária ao longo do bipartidarismo a causa deste padrão? Será que por trás (ou para além) desta variável, não existem outras que possam se caracterizar na real origem do comportamento homogêneo de ex-arenistas e ex-emedebistas? Falta, portanto, confrontar a capacidade explicativa da variável aqui analisada com outras variáveis, levantadas pela literatura especializada.

\section{Hipóteses alternativas}

Até aqui, foi possível estabelecer uma relação direta entre o pertencimento à Arena/MDB e o padrão de tomada de decisão dos constituintes. No entanto, ainda cabe perguntar se a relação identifi-

\section{Quadro 4}

\section{A Origem Socioocupacional dos Remanescentes}

\begin{tabular}{|c|c|c|c|c|c|}
\hline Profissão & Remanescentes & Capital & Sem Posição & Trabalho & Total \\
\hline \multirow[t]{3}{*}{ Manual } & Ex-Arena & - & - & - & - \\
\hline & Ex-MDB & - & - & 1 & 1 \\
\hline & Total & - & - & 1 & 1 \\
\hline Funcionário & Ex-Arena & 12 & 4 & 1 & 17 \\
\hline \multirow[t]{2}{*}{ Público } & Ex-MDB & 1 & 2 & 14 & 17 \\
\hline & Total & 13 & 6 & 15 & 34 \\
\hline \multirow[t]{3}{*}{ Igreja } & Ex-Arena & 1 & - & 1 & 2 \\
\hline & Ex-MDB & 1 & - & 2 & 3 \\
\hline & Total & 2 & - & 3 & 5 \\
\hline \multirow[t]{3}{*}{ Advogado } & Ex-Arena & 21 & 10 & 11 & 42 \\
\hline & Ex-MDB & 5 & 10 & 49 & 64 \\
\hline & Total & 26 & 20 & 60 & 106 \\
\hline \multirow[t]{3}{*}{ Agricultor } & Ex-Arena & 19 & 4 & 1 & 24 \\
\hline & Ex-MDB & 7 & 2 & 6 & 15 \\
\hline & Total & 26 & 6 & 7 & 39 \\
\hline \multirow[t]{3}{*}{ Empresário } & Ex-Arena & 23 & 3 & 3 & 29 \\
\hline & Ex-MDB & 7 & 2 & 6 & 15 \\
\hline & Total & 30 & 5 & 9 & 44 \\
\hline Prof. Liberal & Ex-Arena & 16 & 2 & 4 & 22 \\
\hline \multirow{2}{*}{ Nível superior } & Ex-MDB & 5 & 4 & 19 & 28 \\
\hline & Total & 21 & 6 & 23 & 50 \\
\hline \multirow[t]{3}{*}{ Comunicaçãoo } & Ex-Arena & 5 & 1 & - & 6 \\
\hline & Ex-MDB & - & 1 & 4 & 5 \\
\hline & Total & 5 & 2 & 4 & 11 \\
\hline TOTAL & & 123 & 45 & 122 & 290 \\
\hline
\end{tabular}

Fonte: Banco de Dados SPSS. 
cada é realmente uma relação de causalidade, ou é fruto de uma simples coincidência. É possível que uma terceira variável esteja por trás dessa relação? Na presente seção, pretende-se aprofundar o diálogo com a literatura testando a capacidade explicativa da presente hipótese a partir do confronto com duas hipóteses alternativas: "origem territorial" e "origem socioocupacional" dos deputados.

O Quadro 4 identifica a relação entre a composição social dos remanescentes e seu posicionamento nas votações em exame. Com base nos dados a disposição, não foi possível desmembrar cada categoria para uma análise mais detalhada. Categorias como "empresário" e "agricultor" podem (e é razoável tal presunção) abranger um conjunto muito heterogêneo quanto à origem social dos constituintes. Como não é possível diferenciar aqui, por exemplo, o grande empresário do pequeno, nem o latifundiário do agricultor familiar, optou-se por desmembrar cada categoria em dois grupos: ex-emedebistas e ex-arenistas.

Em estudo sobre o impacto da composição social dos partidos em sua configuração e atuação em três legislaturas (eleitas em 1990, 1994 e 1998), Rodrigues (2002) identifica nos principais partidos políticos representados na Câmara dos Deputados uma significativa congruência entre atuação legislativa, composição social e posicionamento ideológico. No que tange aos remanescentes, é possível identificar (Quadro 4) que, mesmo quando examinados a partir da sua origem socioocupacional, ex-arenistas e ex-emedebistas mantêm um posicionamento coerente com suas respectivas filiaçôes partidárias. Independentemente da origem ocupacional, os ex-arenistas concentram-se maciçamente no apoio ao capital. A única exceção são os membros da Igreja (pouco representativos) e, em menor medida, os advogados. Mesmo neste grupo, $50 \%$ possui o comportamento esperado, ao passo que $26 \%$ apresenta comportamento desviante. Talvez no grupo oriundo da Arena a origem social se manifeste com mais força. Enquanto agricultores e empresários da Arena apoiam claramente o capital, é possível levantar a hipótese de que uma parcela significativa dos "advogados" pertencente a esse grupo tenha alguma dificuldade em apoiar abertamente uma agenda "conservadora".
Se entre os ex-arenistas é plausível inferir que os advogados sejam aqueles que sofrem maior pressão para ir contra a maioria do grupo, entre os ex-emedebistas, a dificuldade maior encontra-se entre os constituintes oriundos do empresariado e da agricultura. Nas demais categorias, os remanescentes do MDB mantêm o comportamento esperado: tanto agricultores, como empresários oriundos deste partido expressam uma clara divisão, pendendo para o apoio ao capital. É exatamente aqui que a composição social ajuda a dar mais um passo para explicar o comportamento dos constituintes.

A correlação entre a antiga filiação partidária e a origem socioocupacional permite afirmar: 1) que mesmo no interior de cada grupo socioocupacional, a filiação aos antigos partidos é coerente com o posicionamento dos constituintes; e 2) que os casos desviantes se concentram entre os advogados da Arena e os empresários e agricultores do MDB. A antiga filiação explica a regra e a origem socioocupacional, a exceção.

A segunda hipótese relaciona a origem territorial dos deputados ao processo de tomada de decisão. Aqui, a hipótese é a de que deputados de regiôes mais desenvolvidas e urbanizadas seriam mais sensíveis às demandas dos trabalhadores do que deputados eleitos em regióes menos desenvolvidas e sustentadas por uma economia agrária pouco dinâmica. Esta tese foi muito utilizada para analisar a questão da histórica desproporcionalidade existente na distribuição das cadeiras na Câmara dos Deputados entre os estados da federação. Um dos principais efeitos desta desproporcionalidade seria a constituição de legislaturas mais conservadoras. Ao analisar a evolução da desproporcionalidade na distribuição das cadeiras na Câmara dos Deputados, Nicolau traça um panorama desta tese, afirmando que:

Gláucio D. Soares radicaliza a hipótese de $\mathrm{Na}-$ varro de Britto ao defender que a alocação desproporcional das cadeiras da Câmara entre os estados dificulta a implementação de reformas sociais no país: "Efetivamente, ao aumentar artificialmente a representação política de uma cultura política tradicional, atrasada, dominada por líderes locais, frequentemente latifundistas, proprietários rurais, coronéis de todos os tipos, 
ou pessoas de sua escolha ou confiança, o sistema eleitoral terminou por prejudicar a maioria da população destas áreas. Ao aumentar o poder político da elite dirigente desta cultura política rural, tradicional e pré-ideológica, ao super-representar na Câmara e no Senado as áreas desenvolvidas social e politicamente, a legislação diminuiu a possibilidade de aprovação, pelas duas Câmaras, de reformas que viriam a beneficiar a maioria da população rural que habita principalmente estas áreas subdesenvolvidas. Este foi o caso da reforma agrária” (1973: 27-28). Autores que posteriormente trataram do tema (Souza, 1976; Kinzo, 1978; Lamounier, 1983), praticamente repetem os argumentos desenvolvidos anteriormente por Reale (1959), Britto (1965) e Soares (1973). Um ponto comum em todos esses trabalhos é o reconhecimento de que a alocação de cadeiras da Câmara entre as unidades da Federação, por critérios não proporcionais, produz resultados deletérios para o sistema representativo brasileiro (Nicolau, 1997, p. 452).
Tendo em vista este cenário, será que nos estados menos desenvolvidos, tanto ex-arenistas como ex-emedebistas votam contra os interesses dos trabalhadores, e nos estados mais desenvolvidos, a maioria em ambos os grupos vota a favor dos trabalhadores? Ao identificar o padrão de voto dos remanescentes por partido e por região de origem, o Quadro 5 permite identificar claramente qual das variáveis possui maior poder explicativo.

Em uma primeira leitura, há evidente equilíbrio entre os deputados que apoiam os trabalhadores e os que apoiam os empregadores. Tomando como referência os deputados que se posicionaram claramente no conjunto das votaçôes, identifica-se que no somatório das regiōes (e em números absolutos) a paridade é quase absoluta (123 deputados pró-capital e 122 pró-trabalho). Ao desagregar estes dados, observa-se que esse equilíbrio também se manifesta em cada região. ${ }^{8}$ A única exceção ocorreu na região Norte, onde, entre os deputados com posição definida, a grande maioria é formada pelos apoiadores dos empregadores (mesmo nesta regiāo, a tendência a um apoio ao capital é mui-

\section{Quadro 5}

\section{A Origem Territorial dos Remanescentes}

\begin{tabular}{llllll}
\hline Região & Remanescentes & Capital & Sem posição & Trabalho & Total \\
\hline Norte & Ex-Arena & 11 & 3 & 1 & 15 \\
& Ex-MDB & 3 & 6 & 3 & 12 \\
& Total & 14 & 9 & 4 & 27 \\
\hline \multirow{2}{*}{ Nordeste } & Ex-Arena & 36 & 12 & 10 & 58 \\
& Ex-MDB & 5 & 4 & 28 & 37 \\
& Total & 41 & 16 & 38 & 95 \\
\hline \multirow{2}{*}{ Centro-oeste } & Ex-Arena & 10 & 3 & 1 & 14 \\
& Ex-MDB & 2 & - & 6 & 8 \\
& Total & 12 & 3 & 7 & 22 \\
\hline Sudeste & Ex-Arena & 23 & 3 & 7 & 33 \\
& Ex-MDB & 14 & 9 & 37 & 60 \\
& Total & 37 & 12 & 44 & 93 \\
\hline Sul & Ex-Arena & 17 & 3 & 2 & 22 \\
& Ex-MDB & 2 & 2 & 27 & 31 \\
& Total & 19 & 5 & 29 & 53 \\
\hline TOTAL & & 123 & 45 & 122 & 290 \\
\hline
\end{tabular}

Fonte: Banco de Dados SPSS. 
to maior entre os remanescentes da Arena do que entre os remanescentes do MDB). Nas demais regiōes (Nordeste, Centro-Oeste, Sudeste e Sul), o equilíbrio entre os deputados é digno de nota. Tal constatação permite afirmar que a origem territorial dos deputados não possui relação direta com o seu posicionamento nas votações analisadas. Cabe também ressaltar que o índice de deputados sem posicionamento claro é minoritário entre os remanescentes de ambos os partidos em todas as regióes.

Analisando-se agora a relação entre região de origem e antiga filiação partidária, identifica-se claramente (e mais uma vez) o comportamento coerente de ex-arenistas e ex-emedebistas nas votações em questão. $\mathrm{O}$ posicionamento dos ex-arenistas pró-capital é uma constante que perpassa todas as regiões do país. Não importa qual é a origem territorial de um arenista - o padrão de votação se repete em todas as regiôes. Mesmo nos estados mais industrializados eles sustentam um padrão de votação pró-capital.

Com relação aos remanescentes do $\mathrm{MDB}$, o padrão de posicionamento também está nitidamente cristalizado. Como afirmado anteriormente, apenas a região Norte é exceção, uma vez que o percentual de deputados sem posição definida é alto $(50 \%$ da bancada) e há nítida divisão entre apoiadores de cada grupo (trabalho/capital). Como o percentual de remanescentes da região Norte é muito pequeno em relação ao total de remanescentes eleito nas demais regiōes e como nas demais regiōes o padrão é claro pró-trabalho, pode-se afirmar que o posicionamento dos ex-emedebistas também é uma constante que perpassa as fronteiras regionais.

\section{Consideraçóes finais: "Quem foi quem na Constituinte"?}

O objetivo principal deste artigo foi testar a hipótese de que o pertencimento prévio dos deputados à Arena ou ao MDB explica o voto dos remanescentes nas votaçôes da ANC que demandaram um posicionamento ideológico definido. $\mathrm{O}$ fato de a filiação partidária no contexto da Constituinte não explicar o voto dos constituintes é consenso na literatura. Mas a questão latente incide sobre como explicar tal fenômeno. Parte da literatura diz que se trata da fragilidade dos partidos políticos brasileiros, como se isto bastasse como explicação. Este artigo buscou dar um passo além neste debate. $\mathrm{O}$ objetivo aqui não foi marcar mais uma vez a tese da fragilidade dos partidos, mas, sim, identificar e explicar suas causas, buscando apreender o comportamento aparentemente "caótico" dos deputados federais no contexto da Constituinte. $\mathrm{Na}$ análise da dinâmica da ANC (ao menos no que se refere às votaçôes envolvendo a relação capital/trabalho), o estudo dos remanescentes de Arena e MDB mostrou-se crucial para explicar o padrão de votação desses deputados.

Análises anteriores já haviam demonstrado que os partidos mais afetados pela indisciplina nas votações foram PMDB e PTB (Quadro 1). Por meio do mapeamento do comportamento de ex-arenistas e ex-emedebistas, foi possível demonstrar: a) que ao contrário dos não remanescentes, os remanescentes possuem posicionamentos bem definidos e diametralmente opostos (Quadro 2); e $b$ ) que essa unidade entre ex-emedebistas e, principalmente, ex-arenistas explica a divisão interna no PMDB e no PTB (Quadro 3).

Depois, a hipótese foi testada em seu poder explicativo a partir do confronto com duas variáveis que poderiam explicar o comportamento dos remanescentes: "origem socioocupacional" e "origem territorial”. Identificou-se que ex-arenistas e ex-emedebistas mantêm seu posicionamento praticamente inalterado, independentemente de sua origem socioocupacional e territorial, confirmando a capacidade explicativa da variável aqui analisada.

Por fim, a confirmação da presente hipótese traz consigo uma questão relevante: se os ex-arenistas possuem uma coesão ideológica e programática digna de nota, por que não se mantiveram unidos em um grande partido?

Pode-se responder a esta questão a partir de vários pontos de vista. A primeira hipótese (e talvez a mais importante) é a de que interesses eleitorais inviabilizem tal projeto. Um grande partido conservador no Brasil pressuporia a coexistência em uma mesma legenda partidária de lideranças/famílias políticas rivais no âmbito municipal e regional (Madeira, 2006). Ao analisar o contexto imediata- 
mente anterior à instauração do Ato Institucional n. 2 pelo regime militar, Filho (1975) e Krieger (1976) afirmam que para viabilizar a construção de um partido amplamente majoritário em nível nacional e de apoio ao regime os militares tiveram que criar uma série de mecanismos para permitir a coexistência de lideranças políticas rivais em nível local. Assim, a sublegenda foi crucial para viabilizar a criação da Arena. Com o retorno ao multipartidarismo, praticamente todos os mecanismos institucionais e a dinâmica de relação regime/partido, que mantinham as elites políticas sob uma mesma legenda, desapareceram. E justamente para evitar a fragmentação das forças que apoiavam o regime novos mecanismos foram postos em prática para impedir o processo de fragmentação.

Power (2000) apresenta outro argumento explicativo, ao afirmar que os ex-arenistas se caracterizariam por um comportamento muito mais reativo do que proativo. Os políticos conservadores teriam, assim, muito mais capacidade de defender o status quo do que de propor mudanças que atendessem aos seus interesses. Também é preciso levar em conta variáveis conjunturais importantes como, por exemplo, a escolha traumática de Paulo Maluf pelo PDS, as negociações em torno da candidatura Tancredo Neves, sua morte e a posse de José Sarney. Tudo isto somado à percepção de que permanecer associado ao regime militar poderia representar um custo político elevado.

Várias são as hipóteses a partir das quais se pode dar uma resposta àquela questão - tema, portanto, para trabalhos futuros. A discussão proposta neste artigo em contraponto às hipóteses levantadas pela literatura a respeito mostra que a viabilidade de um partido conservador em nível nacional talvez não dependa apenas da existência de unidade ideológica...

\section{Notas}

1 Utiliza-se aqui a seguinte distinção entre disciplina e coesão encontrada em Bowler, Farrel e Katz (1999): coesão diz respeito ao grau de homogeneidade das preferências iniciais dos deputados, já disciplina refere-se à capacidade de cada partido de impor um padrão unificado de votação à sua bancada.
2 "Período que o trabalhador dispõe para reclamar do empregador eventuais lesôes de seus direitos trabalhistas. O texto aprovado tem duas formas de prescrição: uma relativa ao direito de reclamar, que se inicia a partir da lesão até dois anos após a cessação do contrato de trabalho; a outra se refere aos créditos que resultam dessa lesão, os quais prescrevem a cada cinco anos" (Diap, 1988 p. 34).

3 "É a organização dos trabalhadores por local de trabalho, para a defesa de seus interesses e intervenção democrática, por intermédio do sindicado, para obter informaçôes administrativas e dados econômico-financeiros sobre a empresa" (Diap, 1988 p. 32).

4 "É a garantia da participação dos trabalhadores e empregadores, de forma paritária, nos órgãos onde os seus interesses profissionais ou previdenciários sejam objeto de discussão e deliberação" (Diap, 1988 p. 34).

5 "É a garantia constitucional de que os direitos e garantias fundamentais onde se incluem os direitos sociais dos trabalhadores, têm aplicação imediata". (Diap, 1988 p. 31).

6 Lembrando sempre que a homogeneidade identificada no PDS e PFL deve-se muito ao comportamento dos ex-arenistas.

7 Embora se possa levantar a hipótese de que em uma disputa capital/trabalho, seja plausível que o grande e o pequeno empresário estejam lado a lado.

8 Caso esse equilíbrio no agregado fosse resultante de uma distribuição territorial desigual entre apoiadores dos trabalhadores e apoiadores dos empregadores (Sul e Sudeste: pró-trabalho; Norte, Nordeste e Centro-Oeste: pró-capital), a hipótese da territorialidade se confirmaria. Como apenas na região Norte foi possível identificar esse parâmetro, a territorialidade não pôde explicar o posicionamento dos deputados.

\section{BIBLIOGRAFIA}

ABREU, Alzira; BELOCH, Israel; LATTMAN-WELTMAN, Fernando \& LAMARAO, Sérgio (coords.). (2001), Dicionário histórico-bibliográfico Brasileiro. Rio de Janeiro, FGV-CPDOC.

BONAVIDES, Paulo. (1968), "As eleições cearenses de 1966". Revista Brasileira de Estudos Politicos, 23/24.

BOWLER, Shaum; FARRELL, David \& KATZ, 
Richard. (1999), "Party cohesion, party discipline and parliaments", in (orgs.), Party discipline and parliamentary government, Ohio, Ohio State University.

DIAP - DEPARTAMENTO INTERSINDICAL DE ASSESSORIA PARLAMENTAR. (1988), Quem foi quem na Constituinte: nas questöes de interesse dos trabalhadores. São Paulo, Cortezl Oboré.

DINIZ. ELI. (1982), Voto e máquina política. Rio de Janeiro, Paz e Terra.

FIGUEIREDO, Argelina \& LIMONGI, Fernando. (1999), Executivo e Legislativo na nova ordem constitucional. São Paulo, Editora da FGV.

FILHO, Luís, V. (1975), O governo Castelo Branco. Rio de Janeiro, Biblioteca do Exército/Livraria José Olympio.

HAGOPIAN, Francis. (1979), Political parties in authoritarian Brazil. PhD, Duke University, mimeo.

KINZO, Maria d'Alva Gil. (1988), Oposição e Autoritarismo: gênese e trajetória do $M D B$ 1966/1979. São Paulo, Vértice, Editora Revista dos Tribunais.

KRIEGER, Daniel. (1976). Desde as missöes... saudades, lutas, esperanças. Rio de Janeiro: José Olympio.

LAMOUNIER, Bolívar e CARDOSO, Fernando Henrique (orgs.). (1978), Os Partidos e as Eleiçôes no Brasil. Rio de Janeiro, Paz e Terra.

LEONI, Eduardo. (2002), "Ideologia, democracia e comportamento parlamentar: a Câmara dos Deputados (1991-1998)". Dados - Revista de Ciências Sociais, 45 (3): 361-386.

MADEIRA, Rafael Machado. (2006), Vinhos antigos em novas garrafas: a influência de ex-arenistas e ex-emedebistas no atual multipartidarismo brasileiro. Tese de Doutorado, Universidade Federal do Rio Grande do Sul, mimeo.

MAINWARING, Scott e LIÑAN, Aníbal. (1998), "Disciplina partidária: o caso da Constituinte". Lua Nova, Número 44.

MELHEM, Célia S. (1998), Política de Botas Amarelas: O MDB/PMDB paulista de 1965 a 1988. São Paulo, Editora Hucitec - USP.

NICOLAU, Jairo. (1997). "As distorções na representação dos estados na Câmara dos
Deputados brasileira”. DADOS, 40 (3): 441-464. Disponível em <http://www.scielo.br/scielo.php?script $=$ sci_arttext\&pid $=$ S0011-52581997000300006 $>$, acessado em 25/3/2010.

PIERSON, Paul. (2004), "Long-term processes". Politics in Time: history, institutions, and social analysis. Princeton Oxford, Princeton University Press.

POWER, Timothy. (2000), The political right in postauthoritarian Brazil: elites, institutions and democratization. Pennsylvania State University press.

RODRIGUES, Leôncio M. (1987), Quem é quem na Constituinte. Uma análise sócio-política dos partidos e deputados. São Paulo, OESP-Maltese. (2002), Partidos, Ideologia e Composição Social: um estudo das bancadas partidárias na Câmara dos Deputados. São Paulo, Edusp. SOUZA, Celina. (2001), "Federalismo e descentralização na Constituinte de 1988: processo decisório, conflito e alianças". Dados - Revista de Ciências Sociais, 44(3).

TRINDADE, Hélgio. "Eleições e partidos no Rio Grande do Sul: do sistema multipartidário à criação do bipartidarismo (1950-1976)", in David Fleischer (org.), Os partidos politicos no Brasil, Brasília, Editora da Universidade de Brasília. 


\section{A ATUAÇÃO DE EX-ARENISTAS E EX-EMEDEBISTAS NA ASSEMBLEIA NACIONAL CONSTITUINTE}

\section{Rafael Machado Madeira}

Palavras-chave: Arena; MDB; Ideologia; Transição democrática; Assembleia Nacional Constituinte

Qual foi o comportamento dos deputados federais remanescentes de Arena e $\mathrm{MDB}$ na Assembleia Nacional Constituinte? Até que ponto a análise do histórico de filiação partidária constitui-se em variável relevante para se entender o processo de tomada de decisão em plenário em votações importantes? Estas premissas são o ponto de partida para análise desenvolvida neste artigo. Para tanto, tomou-se como parâmetro para o exame a coletânea de algumas das principais votaçóes nominais ocorridas elaboradas pelo Diap (Departamento Intersindical de Assessoria Parlamentar).

\section{FORMER-ARENISTAS AND FORMER-EMEDEBISTAS PERFORMANCE IN THE NATIONAL CONSTITUENT ASSEMBLEY}

\section{Rafael Machado Madeira}

Keywords: Arena; MDB; Ideology; Democratic transition; National Constituent Assembly.

Which was the behavior of the remaining representatives of Arena and MDB in the National Constituent Assembley? To what extent the analysis of partisan affiliation history is a good variable to understand the decision making process in important plenary assembly voting? The study points out that beyond partisan affiliations, having been affiliated to ARENA or to MDB consists in a relevant variable to predict the choices of the great majority of former-arenistas and of former-emedebistas during the National Constituent Assembley, no matter their respective partisan affiliations at voting moments.

\section{LA PERFORMANCE DES EX-ARENISTAS ET DES EX-EMEDEBISTAS DANS L'ASSEMBLÉE NATIONALE CONSTITUANTE}

\author{
Rafael Machado Madeira
}

Mots-clés: Arena; MDB; Idéologie; Transition démocratique; Assemblée Nationale Constituante.

Quel a été le comportement des députés fédéraux restants de l'Arena et du MDB dans l'Assemblée Nationale Constituante? Jusqu'à quel point l'analyse de l'historique de la filiation partidaire constitue une variable importante pour comprendre le processus de prise de décision dans assemblée lors de votations importantes? Ces prémisses sont le point de départ de l'analyse développée dans cet article. Pour répondre à ces questions, nous avons adopté comme paramètre l'ensemble de certains des principaux votes nominaux qui ont eu lieu et qui ont été enregistrés par le Diap (Département Intersyndical de Conseil Parlementaire). 